\title{
Analisa Unjuk Kerja Heat Recovery Steam Generator (HRSG) dengan Menggunakan Pendekatan Porous Media di PLTGU - Jawa Timur
}

\author{
Nur Rima Samarotul Janah, Harsono Hadi dan Nur Laila Hamidah \\ Departemen Teknik Fisika, Fakultas Teknologi Industri, Institut Teknologi Sepuluh Nopember \\ e-mail:rima.janah@gmail.com, nurlaila@its.ac.id
}

\begin{abstract}
Abstrak-Untuk meningkatkan produksi energi listrik maka komponen-komponen utama Pembangkit Listrik Tenaga Gas dan Uap (PLTGU) haruslah beroperasi secara optimal. Salah satu komponen utama dari PLTGU adalah Heat Recovery Steam Generator (HRS G). HRSG memiliki beberapa komponen utama yaitu superheater, evaporator dan economizer yang tersusun atas tube-tube yang memiliki struktur dan jumlah tertentu yang mempengaruhi performa HRSG. Pada penelitian ini dilakukan analisa unjuk kerja HRSG dengan menggunakan pendekatan porous media. Pada penelitian ini dilakukan tiga variasi yaitu variasi satu dengan jumlah tube aktual sesuai dengan real plant HRS G yang terdapat di PLTGU - Jawa Timur dengan jumlah tube 6976 buah. Variasi kedua yaitu dengan menambahkan tube sehingga jumlah tube total menjadi 7116 buah. Variasi ketiga yaitu mengurangi jumlah tube sehingga jumlah tube total menjadi 6836 buah. Jumlah tube ini berpengaruh pada jumlah tube pada setaip komponen di HRSG. Pada variasi I suhu HRSG yang ditunjukkan oleh suhu pada $H P$ superheater II adalah 741 $\mathrm{K}$, sedangkan suhu pada variasi II adalah $745 \mathrm{~K}$ dan suhu pada variasi III adalah 741 K. Suhu pada variasi II lebih besar dibandingkan dengan variasi I dan II dikarenakan variasi II memiliki jumlah tube yang lebih banyak sehingga area perpindahan panas yang dimiliki variasi II lebih besar. Kecepatan aliran outlet pada variasi I adalah $3,442 \mathrm{~m} / \mathrm{s}$, variasi II $3,463 \mathrm{~m} / \mathrm{s}$ dan variasi III $3,319 \mathrm{~m} / \mathrm{s}$. Variasi II memiliki kecepatan yang lebih besar dibandingkan dengan variasi I dan III dikarenakan luasan bidang yang dilewati semakin kecil seiringnya dengan bertambahnya jumlah tube.
\end{abstract}

Kata kunci-HRSG, porous media, tube, suhu, kecepatan.

\section{PENDAHULUAN}

U NTUK meningkatkan produksi energi listrik maka komponen-komponen utama Pembangkit Listrik Tenaga Gas dan Uap (PLTGU) haruslah beroperasi secara optimal. Salah satu komponen utama dari PLTGU adalah Heat Recovery Steam Generator (HRSG). [1] HRSG merupakan boiler yang memanfaatkan energi panas sisa gas buang suatu turbin gas untuk memanaskan air dan mengubahnya menjadi uap. HRSG memiliki beberapa komponen utama salah satunya yaitu heat exchanger yang terdiri dari superheater, evaporator, dan economizer. Superheater, evaporator, dan economizer tersusun atas tube-tube yang memiliki struktur dan jumlah terterntu.

Pada penelitian sebelumnya telah dilakukan penelitian dalam bidang performansi HRSG. Dari kebanyakan riset yang telah dilakukan, metode yang digunakan yaitu metode heat and mass balance. Seperti penelitian yang dilakukan oleh Slamet Priyatmojo, dkk (2016) mengenai analisa efisiensi HRSG unit 1 di PT. PLN, dan dari penelitian ini didapatkan nilai efisiensi HRSG yang dipengaruhi oleh perubahan heat rate gas turbine. Penelitian lain mengenai performansi HRSG dilakukan oleh Eflita Yohana (2012), pada penelitian ini dilakukan analisa efesiensi low pressure HRSG, pada penelitian ini didapatkan nilai efesiensi HRSG dipengaruhi oleh kondisi insulasi pada dinding HRSG, korosi pada pipapipa dan diverter damper.

Selain itu terdapat penelitian yang dilakukan oleh Viki Wahyu E, dkk (2012), pada penelitian ini dilakukan analisa unjuk kerja secondry superheater PLTGU dan evaluasi peluang effectiveness dengan cara variasi jarak, jumlah dan diameter tube. Pada penelitian ini analisa dilakukan menggunakan metode Log Mean Temperature Different dan NTU. Dari penelitian ini didapatkan bahwa semakin meningkat jumlah tube yang dipasang maka akan semakin memperluas area perpindahan panas yang terjadi yang akan mempengaruhi effectiveness perpindahan panas menjadi semakin baik.

Performa HRSG dipengaruhi oleh jumlah tube pada masing-masing komponen di HRSG yang memungkinkan terjadinya perpindahan panas pada tube-tube tersebut, maka dari itu dilakukan analisa unjuk kerja HRSG menggunakan pendekatan porous media. Dikarenakan banyaknya tube yang meyusun setiap komponen HRSG maka pembuatan geometri HRSG akan memiliki kerumitan yang tinggi apabila menggunakan metode meshing biasa. Oleh karena itu dilakukan permodelan menggunakan Computational Fluid Dynamics (CFD) dengan pendekatan porous media.[2]

Oleh karena itulah pada studi ini dilakukan analisa unjuk kerja Heat Recovery Steam Generator (HRSG) dengan menggunakan pendekatan porous media di PLTGU - Jawa Timur. 


\section{METODOLOGI}

\section{A. Pembuatan Geometri}

Pada tahap ini dilakukan pembuatan geometri HRSG di CFD sesuai dengan gambar teknik HRSG pada PLTGU - Jawa Timur.

Tabel 1.

Geometri komponen HRSG

\begin{tabular}{lccc|}
\hline \hline \multicolumn{1}{c}{ Komponen } & $\begin{array}{c}\text { Panjang } \\
(\mathrm{m})\end{array}$ & $\begin{array}{c}\text { Lebar } \\
(\mathrm{m})\end{array}$ & $\begin{array}{c}\text { Tinggi } \\
(\mathrm{m})\end{array}$ \\
\hline Preheater & 16,386 & 7,254 & 1,427 \\
LP Economizer & 16,386 & 7,254 & 1,111 \\
LP Evaporator & 16,386 & 7,254 & 1,843 \\
HP Economizer & 16,386 & 7,254 & 1,586 \\
HP Evaporator & 16,386 & 7,254 & 2,297 \\
HP Superheater I & 16,386 & 7,254 & 1,033 \\
HP Superheater II & 16,386 & 7,254 & 0,757 \\
\hline \hline & \\
\hline
\end{tabular}

Gambar 1. Geometri HRSG

\section{B. Meshing}

Meshing adalah pembagian geometri menjadi elemenelemen kecil. Ukuran mesh akan mempengaruhi tingkat ketelitian dan daya komputasi analisa pada CFD. Apabila mesh dibuat sekecil mungkin maka hasil analisa yang didapatkan akan semakin teliti, namun akan dibutuhkan daya komputasi yang semakin besar.

\section{Penentuan General Condition dan Boundary Condition}

Pada tahap ini dilakukan setup untuk general condition yaitu pemilihan energy equation, pemilihan turbulance

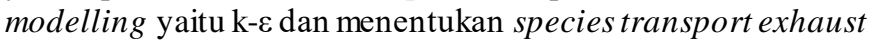
gas di model HRSG.

\section{Material}

Dalam penelitian ini dipilih material sesuai dengan data komposisi exhaust gas yang didapatkan di real plant HRSG PLTGU - Jawa Timur. Sedangkan untuk material kontruksi porous zone digunakan material baja (steel) sesuai dengan material tube yang terdapat di real plant HRSGPLTGU - Jawa Timur.

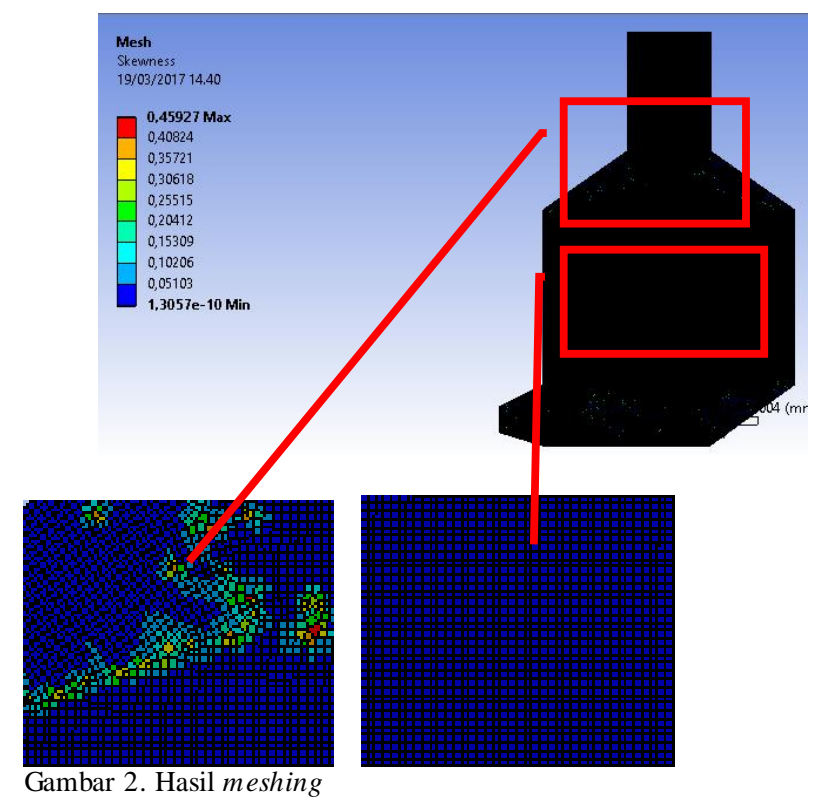

Tabel 2.

Boundary condition

\begin{tabular}{ll}
\hline \hline \multicolumn{1}{c}{ Karakteris tik } & \multicolumn{1}{c}{ Nilai } \\
\hline Temperatur exhaust gas inlet $(\mathrm{K})$ & 796 \\
\hline Laju aliran massa $(\mathrm{kg} / \mathrm{s})$ & 440,4 \\
\hline \hline
\end{tabular}

Tabel 3 .

Species exhaust gas

\begin{tabular}{clcc}
\hline \hline No. & \multicolumn{1}{c}{ Nama } & Rumus Kimia & $\begin{array}{c}\text { Konsentrasi } \\
(\% \text { mol })\end{array}$ \\
\hline 1. & Karbon dioksida & $\mathrm{CO}_{2}$ & 0,49 \\
\hline 2. & n-hexane & $\mathrm{C}_{6} \mathrm{H}_{14}$ & 3,06 \\
\hline 3. & n-butane & $\mathrm{C}_{4} \mathrm{H}_{10}$ & 95,35 \\
\hline 4. & Propane & $\mathrm{C}_{3} \mathrm{H}_{8}$ & 0,81 \\
\hline 5. & Methane & $\mathrm{CH}_{4}$ & 0,12 \\
\hline 6. & Ethane & $\mathrm{C}_{2} \mathrm{H}_{6}$ & 0,02 \\
\hline 7. & Nitrogen & $\mathrm{N}_{2}$ & 0,15 \\
\hline \hline
\end{tabular}

\section{E. Porous Media}

Pada tahap ini, komponen HRSG yang berupa kumpulan tube-tube dianggap sebagai sebuah volume yang berlubang atau disebut juga porous media. Pengaturan porous media dilakukan dimasing-masing komponen yaitu preheater, economizer, evaporator dan superheater.

Nilai yang dimasukkan pada porous media yaitu nilai porosity dan inertial resistance. Pada studi ini dilakukan tiga buah variasi yaitu variasi pertama dengan jumlah tube aktual sesuai dengan real plant HRSG yang ada di PLTGU - Jawa Timur dengan jumlah tube total 6976 buah. Variasi kedua yaitu dengan menambahkan tube pada setiap komponen sehingga jumlah tube total menjadi 7116 buah. Variasi ketiga yaitu mengurangi tube pada setiap komponen sehingga jumlah tube total menjadi 6836 buah. Hal ini menyebabkan masingmasing variasi memiliki nilai porosity yang berbeda-beda. 
Tabel 4

Porosity

\begin{tabular}{lccc}
\hline \hline \multirow{3}{*}{ Komponen } & \multicolumn{3}{c}{ Porosity } \\
\cline { 2 - 4 } & Variasi & Variasi & Variasi \\
& I & II & III \\
\hline Preheater & 0,947 & 0,946 & 0,948 \\
LP Economizer & 0,993 & 0,992 & 0,994 \\
LP Evaporator & 0,947 & 0,947 & 0,948 \\
HP Economizer & 0,943 & 0,942 & 0,944 \\
HP Evaporator & 0,961 & 0,960 & 0,961 \\
HP Superheater I & 0,984 & 0,983 & 0,985 \\
HP Superheater II & 0,985 & 0,984 & 0,986 \\
\hline \hline
\end{tabular}

\section{ANALISA DATA}

\section{A. Validasi Suhu}

Validasi data simulasi dilakukan dengan membandingkan suhu pada komponen HRSG hasil simulasi dengan suhu real plant HRSG di PLTGU - Jawa Timur. Perbandingan nilai ini dapat dilakukan dengan menggunakan hasil simulasi yang memiliki boundary condition yang sama dengan data yang telah didapatkan dari PLTGU - Jawa Timur. Hal ini dimaksudkan untuk mengetahui apakah hasil simulasi yang kita lakukan telah mendekati kondisi real plant HRSG PLTGU Jawa Timur.

Tabel 5 .

\begin{tabular}{lccc} 
Perbandingan suhu aktual dan simulasi pada setiap komponen \\
\hline \hline Komponen & $\begin{array}{c}\text { Suhu } \\
\text { Aktual } \\
(\mathrm{K})\end{array}$ & $\begin{array}{c}\text { Suhu } \\
\text { Simulasi (K) }\end{array}$ & $\begin{array}{c}\text { Error } \\
(\%)\end{array}$ \\
\hline Preheater & 358 & 350 & 2,23 \\
\hline LP Economizer & 412,4 & 412 & 0,10 \\
\hline LP Evaporator & 432 & 431 & 0,23 \\
\hline \hline
\end{tabular}

\begin{tabular}{lccc}
\multicolumn{5}{c}{ Tabel 5. } \\
Lanjutan & & \\
\hline \hline \multirow{3}{*}{ Komponen } & Suhu & Suhu & Error \\
& Aktual & Simulasi & $(\%)$ \\
& $(\mathrm{K})$ & 534 & 0,37 \\
\hline HP Economizer & 536 & 534 & 0,00 \\
\hline HP Evaporator & 568 & 568 & 0,14 \\
\hline HP Superheater I & 700 & 699 & 0,13 \\
\hline HP Superheater II & 742 & 741 & \\
\hline \hline
\end{tabular}

Pada tabel diatas terlihat bahwa error pada semua komponen di HRSG hasil simulasi kurang dari 10\% sehingga hasil simulasi dapat disimpulkan sudah mendekati kondisi real plant HRSG di PLTGU - Jawa Timur.

\section{B. Pengaruh Jumlah Tube Terhadap Suhu}

Pada Gambar 3 dan Gambar 4 terlihat visualisasi distribusi suhu pada HRSG dengan jumlah total tube variasi I sebanyak 6976 buah, variasi II sebanyak 7116 buah dan variasi III sebanyak 6836 buah. Variasi I memiliki jumlah tube aktual sesuai dengan real plant HRSG yang terdapat pada PLTGU Jawa Timur, Pada kedua gambar tersebut kontur warna merah menunjukkan suhu tertinggi pada HRSG sedangkan kontur warna biru tua menunjukkan suhu terendah pada HRSG. Pada simulasi ini nilai suhu inlet untuk ketiga variasi sebesar $796 \mathrm{~K}$. Pada ketiga variasi ters ebut terjadi perpindahan panas antara exhaust gas dengan heat exchanger sehingga suhu pada exhaust gas semakin keatas atau semakin mendekati preheater akan semakin kecil.
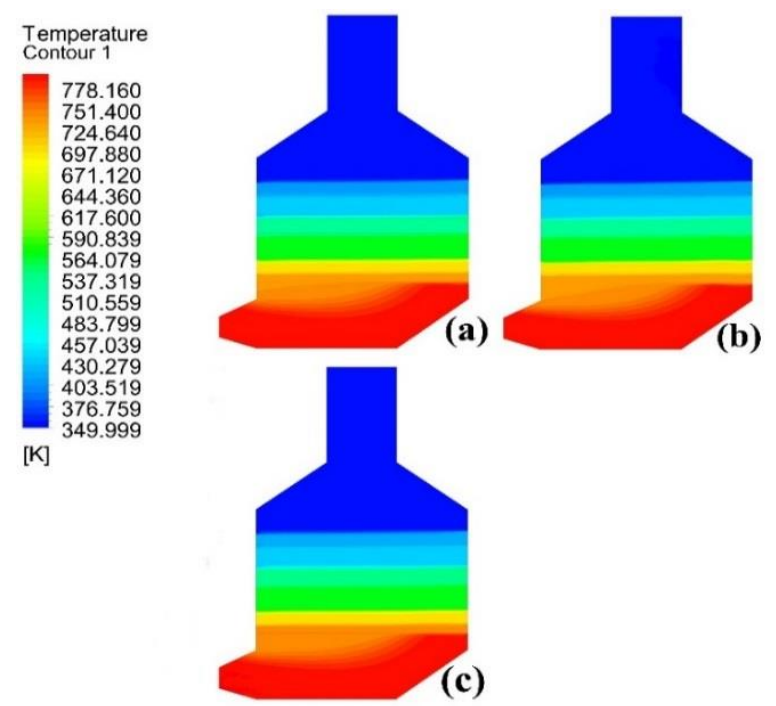

Gambar 3. Kont ur suhu HRSG untuk (a) variasi I (b) variasi II dan (c) variasi III

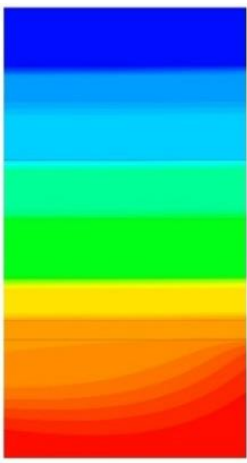

(a)

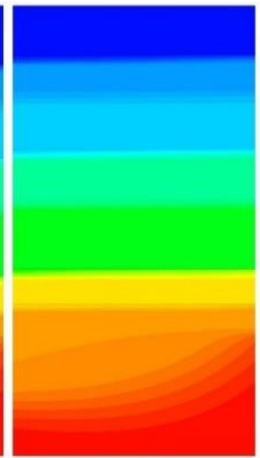

(b)

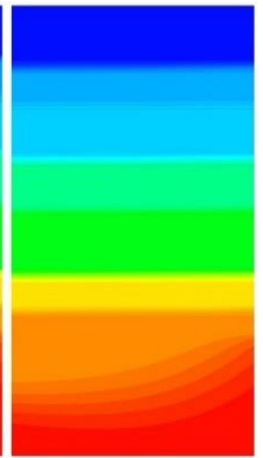

(c)
Gambar 4. Kont ur suhu potongan vertikal HRSG untuk (a) variasi I(b) variasi II dan (c) variasi III

Pada Gambar 3 dan Gambar 4 terlihat visualisasi distribusi suhu pada HRSG dengan jumlah total tube variasi I sebanyak 6976 buah, variasi II sebanyak 7116 buah dan variasi III sebanyak 6836 buah. Variasi I memiliki jumlah tube aktual sesuai dengan real plant HRSG yang terdapat pada PLTGU Jawa Timur, Pada kedua gambar tersebut kontur warna merah menunjukkan suhu tertinggi pada HRSG sedangkan kontur warna biru tua menunjukkan suhu terendah pada HRSG. Pada simulasi ini nilai suhu inlet untuk ketiga variasi sebesar $796 \mathrm{~K}$. Pada ketiga variasi tersebut terjadi perpindahan panas antara exhaust gas dengan heat exchanger sehingga suhu pada exhaust gas semakin keatas atau semakin mendekati preheater akan semakin kecil.

Pada Gambar 3 kontur suhu pada variasi I, variasi II dan variasi III tersebut tidak terlalu terlihat perbedaan warna 
kontur yang mencolok, hal ini dikarenakan perbedaan suhu dari ketiga variasi adalah kecil, tetapi pada Gambar 4 dapat terlihat perbedaan kontur yang cukup jelas pada saat melewati inlet dan menuju superheater II. Hal ini dikarenakan exhaust gas masih mengalami back flow saat melewati inlet dan menjadi uniform saat melewati superheater II. Sealin itu perbedaan suhu yang kecil pada setiap variasi ini diakibatkan oleh perbedaan nilai porosity antar variasi yang juga kecil. Pada Gambar 4 juga terlihat bahwa pada variasi II memiliki warna merah yang lebih luas dibandingkan dengan variasi I dan variasi III. Hal ini dikarenakan jumlah tube pada variasi II yang lebih banyak dibandingkan pada variasi I dan III, sehingga persebaran perpindahan panas pada variasi II terjadi lebih luas apabila dibandingkan pada variasi I dan III.

Tabel 6.

Perbandingan suhu komponen HRSG pada masing-masing variasi

\begin{tabular}{lccc}
\hline \hline \multirow{2}{*}{ Komponen } & \multicolumn{3}{c}{ Suhu (K) } \\
\cline { 2 - 4 } & \multirow{2}{*}{ Variasi I } & Variasi & Variasi \\
& & II & III \\
\hline Preheater & 350 & 342 & 352 \\
LP Economizer & 412 & 408,4 & 411 \\
LP Evaporator & 431 & 423 & 431 \\
HP Economizer & 536 & 527 & 534 \\
HP Evaporator & 568 & 557 & 567,5 \\
HP Superheater I & 699 & 706 & 698 \\
HP Superheater II & 741 & 745 & 741 \\
\hline \hline
\end{tabular}

Dari tabel diatas tersebut terlihat bahwa suhu variasi Ilebih besar daripada variasi II pada komponen preheater, $L P$ economizer, LP evaporator, $H P$ economizer dan $H P$ evaporator. Sedangkan pada komponen $H P$ superheater $I$ dan HP superheater II suhu variasi I lebih kecil dibandingkan suhu variasi II.

Suhu variasi I lebih kecil daripada variasi III pada komponen preheater. Sedangkan pada LP economizer, $H P$ economizer, HP superheater I dan HP superheater II suhu variasi I lebih besar daripada variasi II, dan memiliki suhu yang sama pada komponen LP evaporator dan HP evaporator. Dari ketiga variasi tersebut terlihat bahwa variasi II memiliki suhu HP superheater II yang lebih tinggi yaitu $745 \mathrm{~K}$ dibandingkan dengan suhu HP superheater II pada variasi I dan variasi III yang memiliki suhu $741 \mathrm{~K}$. Selain itu juga terlihat bahwa suhu pada preheater pada variasi I sebesar 350 $\mathrm{K}$, pada variasi II sebesar $342 \mathrm{~K}$ dan suhu variasi 3 sebesar 352 $\mathrm{K}$ sehingga suhu variasi II lebih rendah dibandingkan ketiga variasi, hal ini menunjukkan bahwa pada variasi II perpindahan panas yang terjadi lebih besar dibandingkan dengan variasi I dan III.

Variasi II memiliki suhu yang lebih tinggi dikarenakan jumlah tube pada variasi II yang lebih banyak daripada variasi I dan III sehingga variasi II memiliki luasan perpindahan panas yang lebih besar. Karena memiliki luasan perpindahan panas yang lebih besar, perpindahan panas pada variasi II terjadi lebih baik dibandingkan dengan variasi I dan variasi III.

\section{Pengaruh Jumlah Tube Terhadap Kecepatan Aliran}

Dari Gambar 5 dapat terlihat distribusi kecepatan aliran pada HRSG di variasi I, variasi II dan variasi III. Kontur warna merah menunjukkan kecepatan dengan nilai yang paling tinggi sedangkan kontur warna biru tua menunjukkan kecepatan yang paling rendah. Dari gambar diatas dapat terlihat bahwa pada ketiga variasi terjadi backflow pada aliran didalam HRSG sehingga aliran didalam HRSG ada yang menuju sisi bawah dan ada yang menuju sisi atas. Pada ketiga variasi diatas terjadi fenomena vortex pada bagian tengah HRSG yang memiliki kontur warna biru tua. Variasi II memiliki luasan vortex yang lebih kecil apabila dibandingkan dengan variasi I dan III. Sedangkan variasi I memiliki luasan vortex yang lebih kecil dibandingkan dengan variasi III. Vortex ini diakibatkan aliran pada posisi tersebut mengalami turbulensi yang diakibatkan oleh perbedaan tekanan pada daerah sisi kanan dan sisi kiri. Variasi II memiliki vortex yang lebih kecil dikarenakan variasi II memiliki jumlah tube yang lebih banyak sehingga persebaran aliran dapat lebih merata.
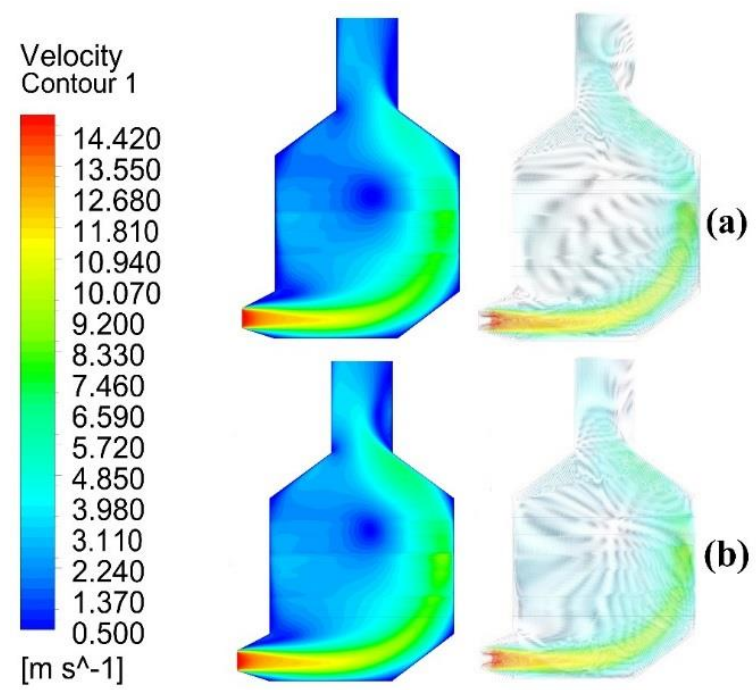

(a)
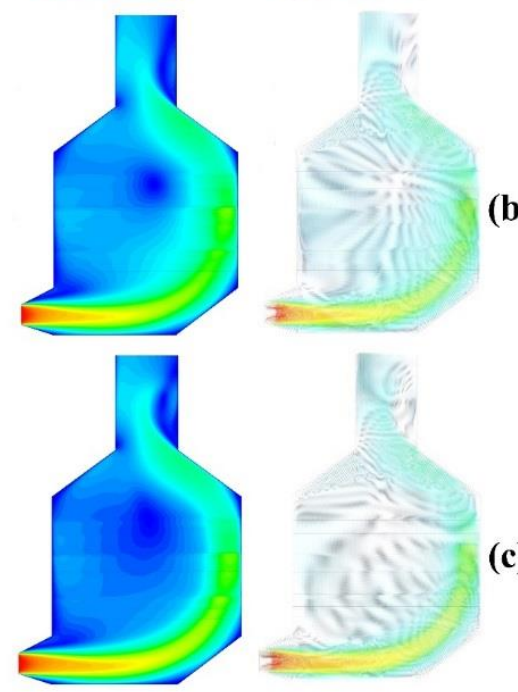

(c)

Gambar 5. Kontur kecepatan HRSGuntuk (a) variasi I (b) variasi II dan (c) variasi III

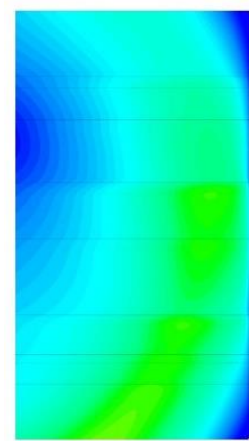

(a)

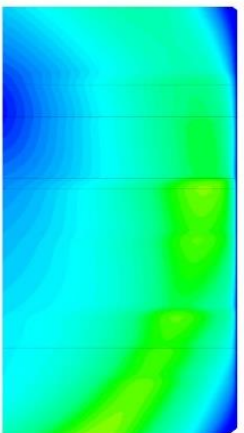

(b)

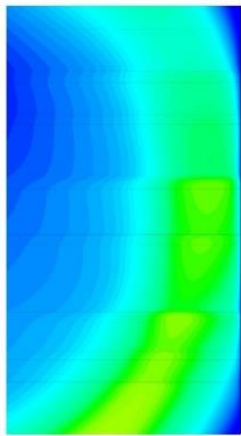

(c)
Gambar 6. Kontur kecepatan HRSG potongan vertikal untuk (a) variasi(b) variasi II dan (c) variasi III 
Pada gambar tersebut terlihat bahwa kecepatan aliran pada variasi II memiliki kontur persebaran kecepatan yang lebih besar dibandingkan dengan variasi I dan III yang dapat terlihat dari kontur warna biru kehijauan yang lebih luas. Sedangkan variasi I memiliki kontur persebaran yang lebih luas apabila dibandingkan dengan variasi III. Persebaran kecepatan aliran pada variasi II lebih baik dikarenakan variasi II memiliki jumlah tube lebih banyak dibandingkan dengan variasi I dan III, sehingga luasan yang dilewati oleh fluida menjadi lebih kecil. Karena luasan yang dilewati lebih kecil menyebabkan kecepatan aliran pada variasi II lebih cepat dan memiliki turbulensi yang lebih besar apabila dibandingkan dengan variasi I dan III. Oleh karena itulah persebaran kecepatan aliran pada variasi II menjadi lebih baik dibandingkan dengan variasi I dan III.

Tabel 7

Perbandingan kecepatan aliran pada masing-masing variasi

\begin{tabular}{lccc}
\hline \multirow{2}{*}{ Komponen } & \multicolumn{3}{c}{ Kecepatan aliran (m/s) } \\
\cline { 2 - 4 } & Variasi I & $\begin{array}{c}\text { Variasi } \\
\text { II }\end{array}$ & Variasi III \\
\hline Preheater & 9,414 & 9,536 & 9,419 \\
\hline LP Economizer & 11,098 & 11,501 & 11,082 \\
\hline LP Evaporator & 12,174 & 12,577 & 12,567 \\
\hline HP Economizer & 13,537 & 13,881 & 13,878 \\
\hline HP Evaporator & 13,728 & 14,119 & 14,109 \\
\hline HP Superheater I & 13,816 & 14,648 & 14,641 \\
\hline HP Superheater II & 14,347 & 14,759 & 14,759 \\
\hline Inlet & 15 & 15 & 15 \\
\hline Outlet & 3,442 & 3,463 & 3,319 \\
\hline \hline
\end{tabular}

Pada Tabel 7 diketahui bahwa kecepatan inlet pada variasi I, variasi II, dan variasi III adalah sama yaitu $15 \mathrm{~m} / \mathrm{s}$. Hal ini dikarenakan nilai input kecepatan yang dimasukkan pada CFD adalah $15 \mathrm{~m} / \mathrm{s}$. Kecepatan outlet pada variasi I sebesar 3,442, variasi II sebesar 3,463 dan variasi III sebesar 3,319, disini terlihat bahwa kecepatan terbesar terjadi pada variasi II. Hal ini sesuai dengan hukum Bernoulli, dimana kecepatan fluida mengalir akan meningkat jika luasan dari bidang yang dilewati semakin kecil. Karena jumlah tube pada variasi II lebih banyak dibandingkan dengan jumlah tube pada variasi I dan III maka akan menyebabkan jarak antar tube pada variasi II semakin kecil. Hal ini juga terlihat pada kecepatan fluida di komponen-komponen HRSG variasi II yang lebih besar dibandingkan dengan variasi I dan variasi III. Hal ini juga dapat terlihat pada variasi I yang memiliki kecepatan lebih besar dibandingkan dengan variasi III, hal ini dikarenakan variasi I memiliki jumlah tube lebih banyak dibandingkan dengan variasi III.

\section{Perpindahan Panas (Heat Transfer) Pada HRSG}

Pada HRSG terjadi perpindahan panas antara fluida exhaust gas dengan fluida didalam tube-tube HRSG. Oleh karena itulah dilakukan analisa perpindahan panas yang terjadi di komponen-komponen HRSG pada ketiga variasi tersebut.
Tabel 8.

Perbandingan perpindahan panas komponen HRSG pada masing-masing variasi

\begin{tabular}{lccc}
\hline \hline \multirow{2}{*}{ Komponen } & \multicolumn{3}{c}{$\mathrm{Q}\left(\mathrm{W} / \mathrm{m}^{2} \mathrm{~K}\right)$} \\
\cline { 2 - 4 } & Variasi I & Variasi II & Variasi III \\
\hline Preheater & 120034,06 & 132609,06 & 111460,20 \\
LP Economizer & 54301,12 & 44584,08 & 57159,08 \\
LP Evaporator & 177193,14 & 174335,18 & 168619,28 \\
HP Economizer & 177193,14 & 171477,23 & 182909,04 \\
HP Evaporator & 442982,84 & 494426,01 & 440696,48 \\
HP Superheater I & 154329,51 & 162903,37 & 157187,46 \\
HP Superheater II & 40011,35 & 65732,94 & 37153,40 \\
Total & 1166045,16 & 1246067,87 & 1155184,94 \\
\hline \hline
\end{tabular}

Pada tabel tersebut perpindahan panas terbesar terjadipada variasi II dengan perpindahan panas total sebesar 1246067,87 $\mathrm{W} / \mathrm{m}^{2} \mathrm{~K}$, lalu diikuti oleh variasi I dengan perpindahan panas total sebesar $1166045,16 \mathrm{~W} / \mathrm{m}^{2} \mathrm{~K}$, lalu yang terakhir variasi III dengan perpindahan panas total sebesar 1155184,94 $87 \mathrm{~W} /$ $\mathrm{m}^{2} \mathrm{~K}$. Selain dari perpindahan panas total dapat terlihat pada perpindahan panas setiap komponen pada variasi II selain $L P$ economizer, LP evaporator dan HP economizer memiliki perpindahan panas yang lebih besar dibandingkan dengan variasi I dan III. Hal ini menunjukkan bahwa perpindahan panas terbesar terjadi pada variasi II yang sesuai dengan distribusi kontur suhu dan kontur kecepatan pada variasi II. Perpindahan panas terbesar terjadi pada variasi II dikarenakan luasan perpindahan panas pada variasi II lebih besar dibandingkan dengan variasi I dan III dikarenakan adanya penambahan tube pada komponen-komponen HRSG.

\section{KESIMPULAN}

Berdasarkan hasil analis a unjuk kerja heat recovery steam generator (HRSG) menggunakan pendekatan porous media di PLTGU - Jawa Timur dapat disimpulkan, yaitu :

a. Suhu HRSG di PLTGU - Jawa Timur dari komponen preheater, LP Economizer, LP evaporator, HP Economizer, HP evaporator, HP superheater I, HP superheater II berturut-turut adalah $350 \mathrm{~K}, 412 \mathrm{~K}, 431 \mathrm{~K}$, $534 \mathrm{~K}, 568 \mathrm{~K}, 699 \mathrm{~K}$, dan $741 \mathrm{~K}$, dengan nilai kecepatan inlet $15 \mathrm{~m} / \mathrm{s}$ dan kecepatan outlet 3,442 m/s.

b. Perpindahan panas yang optimal terjadi pada variasi II dengan jumlah tube 7118 yang ditunjukan dengan suhu pada HP superheater II dan preheater. Hal ini dikarenakan dengan semakin meningkatnya jumlah tube maka semakin besar luas area perpindahan panas

\section{DAFTAR PUSTAKA}

[1] S. H. P. S. and T. Sitepu, "Perancangan Heat Recovery Steam Generator (HRSG) yang Memanfaatkan Gas BuangTurbin Gas di PLT GPT. PLN (Persero) Pembangkitan dan PenyaluranSumatera Bagian Utara Sektor Belawan," e-Dinamis, vol. 8, pp. 233-234, 2014.

[2] K. G. Guler, "Computational Modeling of Fin and Tube Type Vehicle Radiators Based on Porous Medium Approach,”p.3,2014. 